\title{
UROTHELIAL CARCINOMA OF THE URINARY BLADDER MIXED WITH SQUAMOUS DIFFERENTIATION OR SQUAMOUS CELL CARCINOMA IN AREAS WITH SCHISTOSOMIASIS IS SHOWING HIGH RISK OF RECURRENCE AND POOR SURVIVAL BY
}

\author{
MOHAMED WISHAHI*, HOSSAM ELGANZOURY, AMR ELKHOULY \\ and MOHAMED BADAWI.
}

Department of Urology, Theodor Bilharz Research Institute, Kornish ELNil, Embaba, Giza, POB 30, Egypt *Correspondence: Prof. Dr. Mohamed Wishahi Fax. 002 022290 7423, E-mail: moh.weshahy@gmail.com

\begin{abstract}
In schistosomiasis haematobium areas endemic, bladder cancer is the first cause of malignancy in men and fourth in women. The chronic schistosomiasis would lead to variant histologic patterns which manifest in squamous cell carcinoma (SCC) or squamous differentiation (SqD). This study evaluated the clinical outcome after radical cystectomy (RC) in patients with urothelial carcinoma (UC) mixed with SCC or SqD, Comparison was done with two arms of pure UC and pure SCC, indication for RC was muscle-invasive-disease, and evaluation included recurrence, metastases, and overall survival. The data of patients treated with $\mathrm{RC}$ for muscleinvasive-disease, selection was revised for 127 patients with urothelial carcinoma mixed with $\mathrm{SCC} / \mathrm{SqD}$, two comparative arms were 100 patients with pure UC, and 100 patients had pure SCC. Follow up was on 8 months, 3years, and 5 years to detect recurrence, metastasis, and overall survival in the three groups

The results showed that by comparison of disease aggressiveness in the three groups regarding recurrence, metastasis, and overall survival was analysed. Overall survival with mixed tumours was significantly lower than pure UC or SCC, recurrence and metastases were higher in mixed tumour which was an independent factor for poor prognosis and low survival.
\end{abstract}

Key words: Egypt, Schistosomiasis, Bladder cancer, Urothelial carcinoma, Squamous cell carcinoma, Differentiation, Mixed tumour, Prognosis.

\section{Introduction}

Bladder cancer $(\mathrm{BCa})$ is the fifth malignancy in the USA, more than 70, 000 new cases and more than 17, 000 deaths were reported in 2009 (Jamal et al, 2009; Scosyrey et al, 2011) of these muscle-invasive $\mathrm{BCa}$ stage T2-T4 accounted for $10-15 \%$ (Hoskin et al, 2012). In Africa accurate data are not available, most bladder cancer in areas endemic with Schistosomiasis are squamous cell carcinoma (SCC), rather than urothelial carcinoma (UC), SCC tumours present at a locally muscle-invasive of advanced stages of T2-T4, they are usually well differentiated with relatively low incidence of lymphatic or blood metastasis (Heyns et al, 2008).

Bladder cancer is the most common malignancy of the urinary tract, the global world mortality rate is $4 / 100,000$ among men and 1.1/100, 000 among women (Ferlay et al, 2004).

Urothelial carcinoma is the most common histological type and comprises over $90 \%$ of BCa; others included SCC, Adeno carcinoma, small cell carcinoma, sarcoma, carcinosarcoma, lymphoma, and melanoma (Hoskin et al, 2012). Approximately, $75-85 \%$ of patients with $\mathrm{BCa}$ of UC present with disease that is confined to the mucosa (Ta or CIS) or submucosa (T1) (Babjuk et al, 2011). Most deaths from $\mathrm{BCa}$ occur among patients with initial diagnosis of muscle-invasive disease with stages T2-T4.

Bladder carcinoma without known metastasis whether in male or female patients has the standard surgical treatment with 
radical cystectomy (RC) with urinary diversion (Stenzel et al, 2011).

Mixed histological variant of UC would be the association with SCC or squamous differentiation $(\mathrm{SqD})$. The presence of $\mathrm{SCC}$ or SqD in RC specimen would indicate an aggressive behaviour in the post operative follow up in regard to locoregional failure and survival (Honme et al, 2003; Rogers et al, 2005; Kastritis et al, 2006; Alberto et al, 2007; Wasco et al, 2007). The mixed UC with SCC/ SqD are considered an independent factor for recurrence, aggressiveness, and poor survival Chalasani et al, 2009).

The worse prognosis of the mixed tumour compared to pure UR or pure SCC raised awareness for the distinction between pure $\mathrm{UC}$ and the double primary of $\mathrm{UC}$ and $\mathrm{SCC} / \mathrm{SqD}$ that is not detected or not looking for by standard pathological examination of the RC specimen, led to the development of new immunohistochemical techniques to detect SCC or SqD (LopezBeltran et al, 2007; Hayashi et al, 2011; Gruver et al, 2012; Gulmann et al, 2012).

This study aimed at the detection of such combination that direct planning for adjuvant chemo-radio therapy on close observation for development of asymptomatic recurrence.

\section{Patients Materials and Methods}

The study comprised a retrospective and prospective evaluation of three groups of patients who underwent RC and urinary diversion for muscle invasive bladder cancer, the histopathological examination of the RC specimen showed combination of $\mathrm{UC}$ and SCC or SqD, these data were extracted from patients' files in the period from 1995 to 2011. Exclusion criteria were the detection in the $\mathrm{RC}$ specimen positive soft tissue surgical margin, Positive lymph nodes above the common iliac vessels, or presence of metastases.

Patient's data were derived from affiliated hospitals and private hospitals archives. Inclusion criteria were the primary patho- logic diagnosis in transurethral resection of bladder tumour prior to RC or pathological examination of RC specimen was the presence of UC with SCC or SqD with the predominance of UR with varying degrees of cellular differentiation. The total number of cases was 127 cases who had two primary carcinoma of UC with SCC or SqD

Diagnosis of two primary or mixed carcinoma of UR and SCC/SqD based on the identification in the TURB or RC specimen the presence of pearl of SCC with varying degrees of cellular differentiation ranged from well differentiated, medial differentiated, and poorly differentiated (Fig. 1). The squamous differentiation was diagnosed by the presence of keratinised squamous metaplasia, keranenized pear, intercellular bridges, and formation of small or large nests (Fig 2). Pure UC was free from histologic evidences of SCC or $\mathrm{SqD}$ (Fig 3). The predominant cell type in this group of mixed variant of $\mathrm{UC}$ and $\mathrm{SCC} / \mathrm{SqD}$ was UC.

Follow up consisted of visit every three months for the first year, then visit every four months for two successive years, then every six months for five years for the survivals.

Post-operative RC critical information were recurrence-free-survival, cancer specific survival, and patterns of recurrence whether regional, systemic or regionalsystemic. The recurrence-free-survival period was estimated from the time of RC to the post operative date of reporting regional or systemic recurrence, either clinically, ultrasonography, computed tomography scan, bone scan, biopsy, or routine urine sample showing malignancy. The locoregional recurrence was defined as recurrence in the pelvis, illeal pouch, and urethra, pelvic bones including hip bones, or ileal conduit, that was detected by imaging or biopsy.

Metastasis were considered if it appear in the liver, lung, peritoneum, vertebrae, skin, or abdominal lymph nodes, that was de- 
tected by imaging as ultrasonography, CT scan, Bone scan, or biopsy.

Comparison was done between mixed $\mathrm{UC}$ and $\mathrm{SCC} / \mathrm{SqD}$ with another two arms, one of pure UC, and another arm with pure SCC, every arm was composed of 100 patients with matched age and stage, these 200 patients underwent RC and urinary diversion with an initial diagnosis of muscle-invasive carcinoma.

All the 127 patients with mixed UC and $\mathrm{SCC} / \mathrm{SqD}$, and the arm of 100 patients of pure UC, and the other arm of 100 pure SCC (total 327) patients, had a definitive treatment with RC and urinary diversion without adjuvant chemotherapy or radiotherapy.

Pathologic assessment of the RC specimen was done using standard staining technique with haematoxylin and eosin; examination included the mapping of the RC specimen by examination of the following: 1- The tumour itself in 5 parts, 2Adjacent areas, 3- Normally locking urothelium, 4- Prostatic urethra or vagina in female, 5- Lower ureters, 6- Lymph nodes of obturator areas of both sides, 7External lymph nodes on both sides to the bifurcation of the common iliac arteries, and 8- Peri-vesical fat at the trigonal, posterior and domal bladder areas.

\section{Results}

The study comprised 127 patients with UC mixed with SCC and/or SqD in a retrospective study, comparative arms were 100 patients with pure UC and another 100 with pure SCC. The results identified the relevance of mixed histology of UC with SCC and/SqD as an independent factor for progression and the survival in muscleinvasive carcinoma of bladder following RC. Follow-up ranged from 2-5 years. The main emphasis in the follow-up was the time of recurrence, metastases, and the overall survival. Patient characteristics for gender, age, grade of the tumour, stage, lymph node involvement during $\mathrm{RC}$, state of positive soft tissue surgical margin in
RC specimen, are given in table (1).It was apparent that the disease is dominant in men in $90 \%$ of UC, $85 \%$ in SCC, and $76 \%$ in mixed tumours, the disease affected population of relatively young age group. Patients below the age of 55 years were $33 \%$ in UC, $40 \%$ in SCC, and $32 \%$ in mixed tumours, inclusion criteria of the study in the three arms was that the soft tissue surgical margin were free in the $\mathrm{RC}$ specimen and that the supra iliac bifurcation lymph nodes was not involved. The incidence of pelvic lymph node involvement that included obturator and iliac lymph nodes tell the bifurcation of the common iliac vessels on both sides were $30 \%$ in UC, $15 \%$ in $\mathrm{SCC}$, and $34 \%$ in mixed tumours.

Mixed tumours were high grade in $86 \%$ while low and moderate grade was in $13 \%$, pure UC was of high grade in 55\% and low and moderate grade in $45 \%$, Pure SCC was of well differentiated low grade in $80 \%$, while high grade pure SCC was in $20 \%$. All the 127 cases of RC were muscle invasive disease, stage $\mathrm{T} 2$ was found in $65 \%$ of the pure $\mathrm{UC}, 70 \%$ in pure SCC, and in $20 \%$ in mixed tumours, the high stage T34 was predominant in mixed tumours $80 \%$, $35 \%$ in UC, and $30 \%$ in SCC.

Follow up after cystectomy was up to 5 years, the recurrence rate and metastases (Tab. 1), at 8 months local recurrence was $10 \%$ in UC, $7 \%$ in SCC, and $11 \%$ in mixed tumour, at 3 years follow up since time of $\mathrm{RC}$ the recurrence rate was $35 \%$ in $\mathrm{UC}$, $25 \%$ in SCC, and $53 \%$ in mixed tumours, these data were significant for the rapid recurrence in mixed tumours as an independent factor compared to pure UC or pure SCC.

Cancer metastases with or without recurrence was statistically significant for the mixed tumours as a factor for disease progression (Tab. 2), in 3 years follow up the metastatic rate was $86.6 \%$ in mixed tumours, $7 \%$ in SCC and $65 \%$ in UC. In 5 years follow up the highest incidence of 
Table 1: Patient Characteristics

\begin{tabular}{|c|c|c|c|}
\hline Characters & $\begin{array}{c}\mathrm{UC} \\
\text { no. } 100\end{array}$ & $\begin{array}{c}\text { SCC } \\
\text { no. } 100\end{array}$ & $\begin{array}{c}\text { Mixed UC and SCC/SqD } \\
\text { no. } 127\end{array}$ \\
\hline \multicolumn{4}{|l|}{ Sexes } \\
\hline male & $90(90 \%)$ & $85(85 \%)$ & $96(76 \%)$ \\
\hline female & $10(10 \%)$ & $15(15 \%)$ & $30(24 \%)$ \\
\hline \multicolumn{4}{|l|}{ Age } \\
\hline$>55$ & $33(33 \%)$ & $40(40 \%)$ & $41(32 \%)$ \\
\hline$<55$ & $67(67 \%)$ & $60(60 \%)$ & $67(53 \%)$ \\
\hline \multicolumn{4}{|l|}{ Grade } \\
\hline low/medium & $45(45 \%)$ & $80(80 \%)$ & $16(13 \%)$ \\
\hline high & $55(55 \%)$ & $20(20 \%)$ & $110(86 \%)$ \\
\hline Lymph node involvement & $30(30 \%)$ & $15(15 \%)$ & $43(34 \%)$ \\
\hline Positive soft tissue surgical margin & no & no & no \\
\hline \multicolumn{4}{|l|}{ Stage } \\
\hline $\mathrm{T} 2$ & $65(65 \%)$ & $70(70 \%)$ & $25(20 \%)$ \\
\hline $\mathrm{T} 3-\mathrm{T} 4$ & $35(35 \%)$ & $30(30 \%)$ & $102(80 \%)$ \\
\hline
\end{tabular}

Table 2: Recurrence, metastases, and overall survival in patients with pure UC, pure SCC, and mixed UC with $\mathrm{SCC} / \mathrm{SqD}$

\begin{tabular}{|l|c|c|c|}
\hline & $\begin{array}{c}\text { UC } \\
\text { no. } 100\end{array}$ & $\begin{array}{c}\text { SCC } \\
\text { no. } 100\end{array}$ & $\begin{array}{c}\text { Mixed UC and SCC/SqD } \\
\text { no. 127 }\end{array}$ \\
\hline Local recurrence & & & $14(11 \%)$ \\
\hline 8 months & $10(10 \%)$ & $7(7 \%)$ & $67(53 \%)$ \\
\hline 3 years & $35(35 \%)$ & $25(25 \%)$ & $94(74 \%)$ \\
\hline 5 years & $40(40 \%)$ & $30(30 \%)$ & \\
\hline $\begin{array}{l}\text { Metastases with or } \\
\text { without local recur- } \\
\text { rence }\end{array}$ & & & $12(9 \%)$ \\
\hline 8 months & $15(15 \%)$ & $0(0 \%)$ & $110(86 \%)$ \\
\hline 3 years & $65(65 \%)$ & $7(7 \%)$ & $111(90 \%)$ \\
\hline 5 years & $75(75 \%)$ & $32(32 \%)$ & $111(88 \%)$ \\
\hline Survival & & & $28(22 \%)$ \\
\hline 8 months & $95(95 \%)$ & $96(96 \%)$ & $13(10 \%)$ \\
\hline 3 years & $35(35 \%)$ & $88(88 \%)$ & \\
\hline 5 years & $25(25 \%)$ & $55(55 \%)$ & \\
\hline
\end{tabular}

Table 3: Overall survival in pure UC, pure SCC and mixed UC with SCC SpD

\begin{tabular}{|c|c|c|c|}
\hline Survival & $\begin{array}{c}\text { UC } \\
\text { no. } 100\end{array}$ & $\begin{array}{c}\text { SCC } \\
\text { no. } 100\end{array}$ & $\begin{array}{c}\text { Mixed UC and SCC/SqD } \\
\text { no. } 127\end{array}$ \\
\hline 8 months & $95(95 \%)$ & $96(96 \%)$ & $111(88 \%)$ \\
\hline 3 years & $35(35 \%)$ & $88(88 \%)$ & $28(22 \%)$ \\
\hline 5 years & $25(25 \%)$ & $55(55 \%)$ & $14(11 \%)$ \\
\hline
\end{tabular}


metastases was in mixed tumours $90 \%$, followed by UC $75 \%$, and the least was SCC of $17 \%$.

Overall survival (Tab. 3) where the lowest survival was statistically significant in mixed tumours, followed by UC and SCC, overall survival in mixed tumours in 5 years in 127 patients with muscle invasive bladder carcinoma was $11 \%$, survival in SCC was $55 \%$, and in UC $25 \%$.

\section{Discussion}

Generally speaking, $S$ hematobium (SH) in developing countries, particularly in Africa and the Middle East, accounts for the main total burden (Zarzour et al, 2008). This was particularly true in Egypt (AboMadyan et al, 2004).

Urothelial carcinoma often exhibit elements of squamous differentiation or associated with definite SCC, the spectrum of microscopic forms of UC has been expanded recently to include several histological variants, the recognition of which is important to avoid diagnostic misinterpretation, to predict outcome, and to guide the selection of the appropriate therapeutic approach (Rogers et al, 2006; Kastritis et al, 2006; Alberto et al, 2007; Scosxreye et al, 2011). The presence of SqD or SCC within UC of the bladder has an adverse prognostic factor associated with higher local failure rate in patients undergoing $\mathrm{RC}$ for muscle-invasive-cancer (Ehdaie et al, 2012). The present results in retrospective and prospective analysis of 127 patients whom under gone RC for muscle invasivecancer with a comparative two arm of 100 patients with pure UC, and another 100 patients with pure SCC who undergone RC for muscle-invasive-cancer showed that SCC and/or SqD in the cystectomy specimen were predictive of poor cancerspecific-survival, the loss of histological differentiation were predictive of poor overall survival, the results were cohere with other series (follow up in regard to loco-regional failure and survival (Rogers et al, 2005; Kastritis et al, 2006; Wasco et al, 2007; Chalasani et al, 2009).

The present results emphasised the findings that UC with divergent differentiation has a worse prognosis compared to pure $\mathrm{UC}$; pure SCC of the bladder is an uncommon cause of bladder cancer in developed world, accounting for $2.7 \%$ of bladder cancer in recent series (Chalasani et al, 2009). In areas where schitosomiasis is common and chronic bladder infection predominates the incidence of SCC is high and attribute to $55 \%$ of all bladder cancer registry.

\section{Conclusion}

The outcome results showed the clinical significance of association of SCC and $\mathrm{SqD}$ in urothelial tumours where there were evidences that it was an indicator of poor prognosis and poor cancer-specificsurvival, there were significant association between SCC and/ SqD in the urothelial tumour cystectomy specimen and higher tumour grade and stage, the high recurrence and metastatic rate would be attributed to the divert histological pattern of mixed $\mathrm{UC}+\mathrm{SCC} / \mathrm{SqD}$. The aggressive behaviour of $\mathrm{UC}+\mathrm{SCC} / \mathrm{SqD}$ would indicate that there are two primary in the bladder or a variant clinic-pathologic type of bladder carcinoma. The detection of mixed UC with SCC/ SqD is an important element for diagnosis and plan proper treatment strategy. The variant histologic pattern had worse prognosis compared to pure urothelial or pure squamous cell carcinomas.

\section{References}

Abo-Madyan, AA, Morsy, TA, Motawea, SM, 2004: Efficacy of Myrrh in the treatment of schistosomiasis (haematobium \& mansoni) in Ezbet El-Bakly, Tamyia Center, El-Fayoum Governorate, Egypt. J. Egypt. Soc. Parasitol. 34, 2:423-46.

Alberto, AA, Luciano, JN, Marcos, FD, et al, 2007: The role of squamous differentiation in patients with transitional cell carcinoma of 
the bladder treated with radical cystectomy. Int. Braz. J. Urol. 33:339-49.

Babjuk, M, Oosterlinck, W, Sylvester, R, et al, 2011: EAU guidelines on non-muscleinvasive urothelial carcinoma o ft he bladder, the 2011 update. Eur. Urol. 59:997-1008

Chalasani, V, Chin, JL, Izawa, J, et al, 2009: Histologic variants of bladder cancer and nonuruthelial histology in bladder cancer. Can. Urol. Assoc. J. 3:S193-8.

Ehdaie, B, Maschino, A, Shaniat, SF, et al, 2012: Comparative outcome of pure squamous cell carcinoma and urothelial carcinoma with squamous differentiation in patients treated with radical cystectomy. J. Urol. 187: 74-79.

Ferlay, J, Bray, F, Pisani, P, et al, 2002: Glob-can: Cancer incidence, mortality and prevalence worldwide. IARC Base Lyon, IARC Press, France.

Gruver, AM, Amin, MB, Luthringer, DJ, et al, 2012: selective immunohistochemical markers to distinguish between metastatic high-grade urothelial carcinoma and primary poorly differentiated invasive squamous cell carcinoma of the lung. Arch. Path. Lab. Med. 136:1339-46.

Gulmann, C, Paner, GP, Parakh, RS, et al, 2012: Immunohistochemical profile to distinguish urothelial from squamous differentiation in carcinoma of urothelial tract. Hum. Pathol. 8 Epud ahead of print).

Hayashi, T, Sentani, K, Oue, N, et al, 2011: Desmocollin 2 is a new immunohistochemical marker indicative of squamous differentiation in urothelial carcinoma. Histopathol. 59:71021.

Heyns, CF, Van der Merwe, A, 2008: Bladder cancer in Africa. Can. J. Urol. 15:3899-08.

Hoskin, P, Dubash, S, 2012: Bladder conservation for muscle-invasive bladder cancer. Expert. Rev. Anticancer Ther. 12:1015-20.

Honma, I, Masumori N, Sato, E, et al, 2003: Local recurrence after radical cystectomy for invasive bladder cancer: An analysis of predict tive factors. Urology 64:744-8.

Jemal, A, Siegel, R, Wart, E, et al, 2009: Cancer statistics 2009. Cancer J. Clin. 59:22549.

Kastritis, E, Dimopoulos, M, Antonniou, N, et al, 2006: the outcome of patients with advanced pure squamous or mixed squamous and transitional urothelial carcinoma following platinum-based chemotherapy. Anticancer Res. 26:3865-70.

Lopez-Beltran, A, Requena, MJ, AlvarezKindelan, J, et al, 2007: Squamous differentiation in primary urothelial carcinoma of the urinary tract as seen by MAC 387 immunohistochemistry. J. Clin. Pathol. 60:332-35.

Rogers, CG, Paiapattu, GS, Shariat, SH, et al, 2006: Clinical outcome following radical cystectomy for primary nontransitional cell carcinoma of the bladder compared to transitional cell carcinoma of the bladder. J. Urol. 175:2048-53

Scosyreye, E, Ely, BW, Messing, EM, et al, 2011: Do mixed histologic features affect survival benefit from neo-adjuvant platinumbased combination chemotherapy in patients with locally advanced bladder cancer? A secondary analysis of Southwest oncology GroupDirected Integrated study (S8710). BJU Int. 108: 693-99

Stenzel, A, Cowan, NC, DE, Santis, M, et al, 2011: Treatment of muscle-invasive and metastatic bladder cancer: update of the EAU guidelines. Eur Urol. 59: 1009-18

Wasco, MJ, Daignault, S, Zhang, Y, et al, 2007: Urothelial carcinoma with divert histilogic differentiation (mixed histologic features) predict the presence of locally advanced bladder cancer detected at transurethral resection. Urology 70: 69-74

Zarzour, AH, Selim, M, Abd-Elsayed, AA, Hameed, DA, Abdelaziz, MA, 2008: Muscle invasive bladder cancer in Upper Egypt: the shift in risk factors and tumor characteristics. BMC Cancer 8:250-64. 1.

\section{Abbreviations}

UC: Urothelial carcinoma, SCC: Squamous cell carcinoma, SqD: Squamous differentiation, RC: Radical cystectomy, BCa: Bladder cancer

\section{Explanation of figures}

Fig. 1A, B: Urothelial carcinoma with squamous differentiation showing corneous pearl formation and nest formation, X 200.

Fig. 2A, B: Squamous cell carcinoma. X200

Fig. 3: Urothelial carcinoma without SCC or Sq.D. X400. 

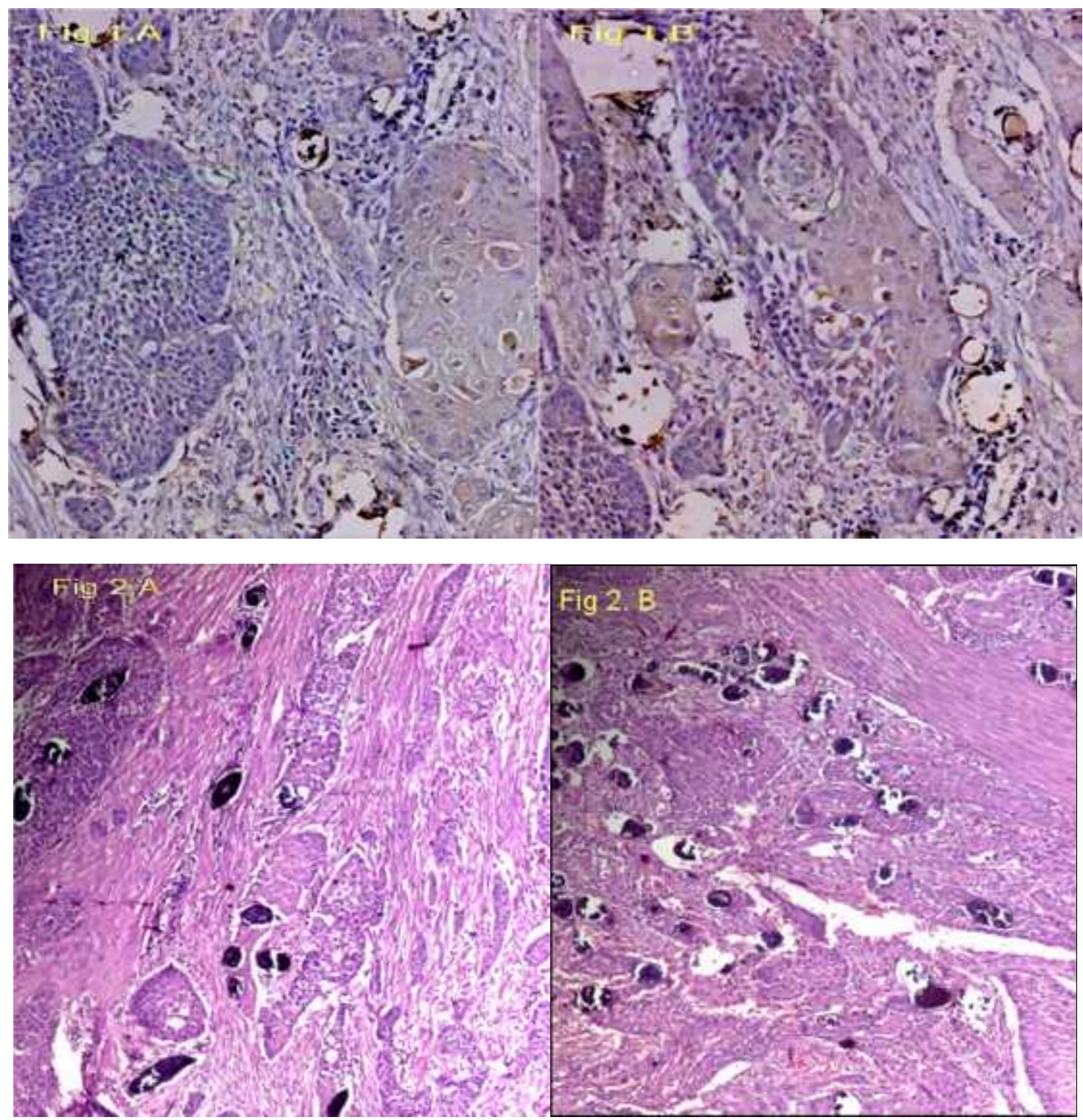

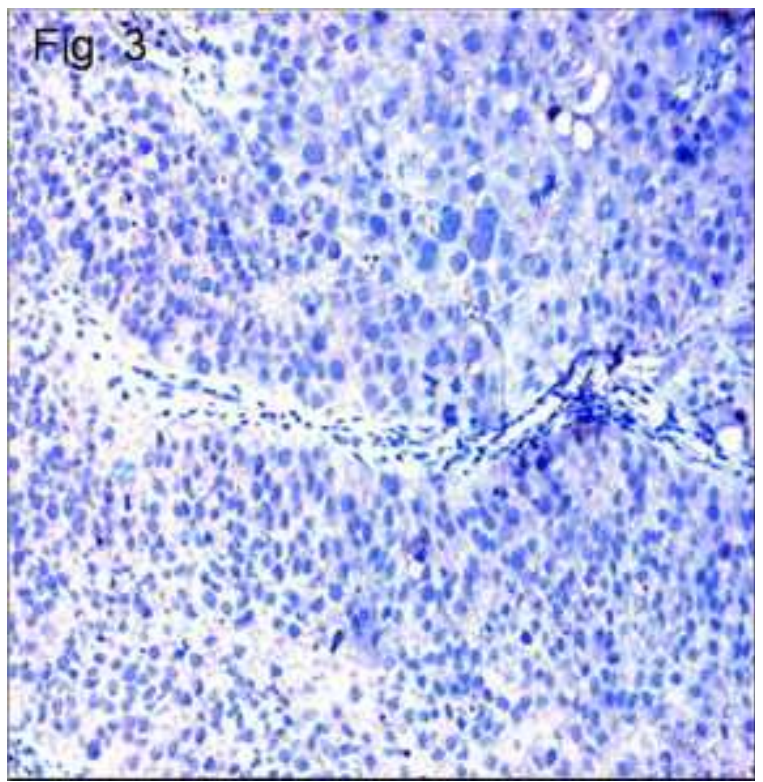

